\title{
Optimized Synthesis Temperature and Time to Obtain Crystalline Carbon Nitride with Enhanced Photocatalytic Activity for Phenol Degradation
}

\author{
Leny Yuliati ${ }^{1,2,3,}$, Mohd Hayrie Mohd Hatta ${ }^{4,5}$, Siew Ling Lee ${ }^{3,4}$, and Hendrik Oktendy Lintang ${ }^{1,2,3}$ \\ ${ }^{1}$ Ma Chung Research Center for Photosynthetic Pigments, Universitas Ma Chung, \\ Villa Puncak Tidar N-01, Malang 65151, East Java, Indonesia \\ ${ }^{2}$ Department of Chemistry, Faculty of Science and Technology, Universitas Ma Chung, \\ Villa Puncak Tidar N-01, Malang 65151, East Java, Indonesia \\ ${ }^{3}$ Center for Sustainable Nanomaterials, Ibnu Sina Institute for Scientific and Industrial Research, \\ Universiti Teknologi Malaysia, 81310 UTM Johor Bahru, Johor, Malaysia \\ ${ }^{4}$ Department of Chemistry, Universiti Teknologi Malaysia, 81310 UTM Johor Bahru, Johor, Malaysia \\ ${ }^{5}$ Foundation in Science, Faculty of Medicine, ASIA Metropolitan University, 81750, Johor Bahru, Johor, Malaysia
}

* Corresponding author:

email:leny.yuliati@machung.ac.id

Received: December 17, 2019

Accepted: March 26, 2020

DOI: $10.22146 / \mathrm{ijc} .52345$

\begin{abstract}
In this work, the crystalline carbon nitride photocatalysts were synthesized by an ionothermal technique with varied synthesis temperature of 500,550 , and $600{ }^{\circ} \mathrm{C}$, and varied synthesis time of 2, 4, and $6 \mathrm{~h}$. Fourier transform infrared spectra showed the successful formation of the prepared carbon nitrides from their characteristic vibration peaks. X-ray diffraction patterns suggested that the same phase of poly(triazine imide) and heptazine could be observed, but with different crystallinity. The optical properties showed that different temperatures and synthesis time resulted in the different band gap energy (2.72-3.02 eV) as well as the specific surface area $\left(24-73 \mathrm{~m}^{2} \mathrm{~g}^{-1}\right)$. The transmission electron microscopy image revealed that the crystalline carbon nitride has a nearhexagonal prismatic crystallite size of about $50 \mathrm{~nm}$. Analysis by high-performance liquid chromatography showed that the best photocatalytic activity for phenol degradation under solar light simulator was obtained on the crystalline carbon nitride prepared at $550{ }^{\circ} \mathrm{C}$ for $4 \mathrm{~h}$, which would be due to the high crystallinity, suitable low band gap energy $(2.82 \mathrm{eV})$, and large specific surface area $\left(73 \mathrm{~m}^{2} \mathrm{~g}^{-1}\right)$. Controlling both the temperature and synthesis time is shown to be important to obtain the best physicochemical properties leading to high activity.
\end{abstract}

Keywords: carbon nitride; crystallinity; phenol degradation; synthesis temperature; synthesis time

\section{- INTRODUCTION}

Phenol is one of the major organic pollutants that exist in the industry effluents [1]. Even though at low concentration, phenol has high toxicity. An alternative method that offers green and clean technology to treat phenol is the photocatalytic degradation process. Many studies have been focused on the development of titanium dioxide $\left(\mathrm{TiO}_{2}\right)$-based photocatalysts for various photocatalytic degradation reactions [2-4], which are mostly due to the high activity of $\mathrm{TiO}_{2}$ under ultraviolet
(UV) irradiation. However, owing to the large portion of visible light in the sunray, the development of visible light active photocatalysts has been an important task in the photocatalysis field. Since $\mathrm{TiO}_{2}$ does not absorb visible light, some modifications are required, such as by doping or making a composite with another visible lightactive semiconductor [5-7]. In addition to these efforts, studies on the potential materials that are visible light active are still highly required. One of the fascinating choices for the visible light active photocatalysts is

Leny Yuliati et al. 
carbon nitride $(\mathrm{CN})$. Even though $\mathrm{CN}$ has been investigated for years, many reported literatures showed that the synthesized $\mathrm{CN}$ was in the amorphous form [814]. While the $\mathrm{CN}$ showed photocatalytic activity under visible light, the $\mathrm{CN}$ with the amorphous phase has been reported to show lower photocatalytic performance in the catalytic process as compared to the crystalline one. A drastic enhancement in the photocatalytic activity of the $\mathrm{CN}$ has been reported to occur over the crystalline $\mathrm{CN}$ either for photocatalytic degradation of organic compounds or for hydrogen production [15-19].

In photocatalysis, the directional flow of electrons depends on the organization of the molecules in the structure concerning their crystalline [20-22]. Moreover, the crystalline structure would demonstrate faster electron movement as the direction is confined. The fast rate of electron diffusion would reduce the trapping and de-trapping effect; thus, the rate of electron-hole recombination would be decreased [23]. In the case of crystalline $\mathrm{CN}$, the enhanced photocatalytic activity could also be additionally caused by the improved light absorption due to the extended $\pi$-conjugated system and the increased rigidity of the polymer backbones [24]. Since the photocatalytic properties are sensibly affected by the crystallinity of the photocatalyst, constructing a crystalline photocatalyst that is active under natural sunlight is a promising work and highly recommended but can be a challenging task to be achieved.

Several methods to produce the crystalline $\mathrm{CN}$ have been examined. Recently, it was reported that the crystalline $\mathrm{CN}$ could be synthesized via an ionic melt polycondensation of urea precursor in the presence of potassium chloride-lithium chloride $(\mathrm{KCl}-\mathrm{LiCl})$ salt melt [15]. Bhunia et al. produced the crystalline carbon nitride by combining the supramolecular aggregation and polycondensation of an ionic melt using melamine, 2,4,6triaminopyrimidine, and $\mathrm{LiCl} / \mathrm{KCl}$ mixture [16]. These two methods produced crystalline $\mathrm{CN}$ having not only the structure of graphitic $\mathrm{CN}$ but also the poly(triazine imide)-like structure [15-16]. The better-ordered structure of the graphitic $\mathrm{CN}$ was observed by using a thermal condensation of melem but must be put under a pure oxygen atmosphere [17]. Another method was also reported involving an additional acidic washing process using hydrogen chloride $(\mathrm{HCl})$ after the polycondensation of melamine in the presence of $\mathrm{KCl}$ and $\mathrm{LiCl}$ [18]. Another synthesis method, a rapid polymerization of melamine without the early heating process, was proposed to produce the crystalline $\mathrm{CN}$ [19]. However, these last-mentioned three methods only produced $\mathrm{CN}$ having the structure of graphitic $\mathrm{CN}$ with a better order in the interlayer stacking and in-plane repeated units. These semi-crystalline $\mathrm{CN}$ materials are usually obtained when the precursor is thermally polymerized [24].

Since we aim to get the crystalline $\mathrm{CN}$, the synthesis method that has been proven to give the structure of crystalline $\mathrm{CN}$ shall be employed. Among the techniques mentioned above, the one using ionothermal technique with the help of $\mathrm{KCl}-\mathrm{LiCl}$ salt melt has been shown to require fewer chemicals to obtain the crystalline $\mathrm{CN}$ having the poly(triazine imide)-like structure [15]. Moreover, the resulted crystalline $\mathrm{CN}$ was confirmed to give higher photocatalytic activity for phenol degradation under visible light than the amorphous $\mathrm{CN}$. However, a detailed study of the optimized synthesis temperature and time for this method has not been addressed yet. In order to optimize the photocatalytic efficiency of the crystalline $\mathrm{CN}$, in this work, the effects of synthesis temperature and time on the properties and photocatalytic activity of the crystalline $\mathrm{CN}$ were investigated. This work demonstrated that the optimized synthesis temperature and time were important parameters to obtain the optimized photocatalytic activity of the crystalline $\mathrm{CN}$. As high as 3.4 times higher photocatalytic activity was observed on the sample synthesized under the optimized conditions than those prepared under the non-optimized one.

\section{- EXPERIMENTAL SECTION}

\section{Materials}

For the preparation of $\mathrm{CN}$ materials, urea $\left(\mathrm{CH}_{4} \mathrm{~N}_{2} \mathrm{O}\right.$, QRëC, 99\%) was used as carbon and nitrogen-rich precursors. Ethanol $\left(\mathrm{C}_{2} \mathrm{H}_{5} \mathrm{OH}, \mathrm{HmBG}\right.$ Chemicals, 99.98\%) was used as a solvent in the 
preparation of $\mathrm{CN}$. For the preparation of crystalline $\mathrm{CN}$, the ionic solvents used were lithium chloride $(\mathrm{LiCl}$, Sigma-Aldrich, 99\%) and potassium chloride (KCl, Fisher Chemicals, $99.5 \%$ ). The model of organic pollutant used for this study was phenol $\left(\mathrm{C}_{6} \mathrm{H}_{6} \mathrm{O}\right.$, Scharlau Chemie, 99.5\%).

\section{Procedure}

\section{Synthesis of crystalline carbon nitride}

The crystalline carbon nitride was prepared in a similar way to the reported literature [15]. In order to investigate the effect of synthesis temperature $(500,550$, and $600{ }^{\circ} \mathrm{C}$ ), other synthesis parameters including the amount of precursor $(2 \mathrm{~g})$, synthesis time $(4 \mathrm{~h})$, and amount of salts melt $(2.74 \mathrm{~g} \mathrm{KCl}, 2.26 \mathrm{~g} \mathrm{LiCl})$ were fixed. The final products were labeled as $\mathrm{CN}-\mathrm{T}$, which were $\mathrm{CN}$ $500, \mathrm{CN}-550$, and $\mathrm{CN}-600$. The synthesis time was varied to 2,4 , and $6 \mathrm{~h}$ to obtain the optimum time. In this part, the amount of precursor $(2 \mathrm{~g})$, reaction temperature $\left(550{ }^{\circ} \mathrm{C}\right)$, and amount of salts melt $(2.74 \mathrm{~g} \mathrm{KCl}$ and $2.26 \mathrm{~g}$ $\mathrm{LiCl})$ were fixed. The final samples were labeled as $\mathrm{CN}-t$ in which $t$ refers to 2,4 , and $6 \mathrm{~h}$.

\section{Characterizations of crystalline carbon nitride}

The prepared $\mathrm{CN}$ materials were characterized using several instruments. The structural properties were identified using a powder X-ray diffractometer (XRD). The XRD patterns were recorded using Bruker D8 Advance with $\mathrm{CuK}_{\mathrm{a}}$ irradiation $(\lambda=1.5406 \AA)$. The optical properties were determined by a diffuse reflectance ultraviolet-visible (DR UV-vis) spectroscopy using a Shimadzu UV-2600 DR UV-vis spectrophotometer with wavelength recorded in the range of 220 to $800 \mathrm{~nm}$. The chemical bonds and functional groups were determined by using a Fourier transform infrared spectroscopy (FTIR, Nicolet-iS50). The technique used in the characterization was the $\mathrm{KBr}$ pellet technique. The nitrogen $\left(\mathrm{N}_{2}\right)$ adsorption-desorption isotherm analysis at $-196.15^{\circ} \mathrm{C}(77 \mathrm{~K})$ using a Quantachrome NOVAtouch LX4 instrument was deployed in order to investigate the specific surface area (SA). All the samples were dried at $100{ }^{\circ} \mathrm{C}$ in the oven before the measurement. For the degassing part, the samples were heated at $180^{\circ} \mathrm{C}$ for $3 \mathrm{~h}$ at the ramp of $10^{\circ} \mathrm{C} / \mathrm{min}$. The best $\mathrm{CN}$ material was also characterized by a transmission electron microscope (TEM, JEOL JEM-2100).

\section{Photocatalytic degradation of phenol}

The photocatalyst $(0.05 \mathrm{~g})$ was dispersed in $100 \mathrm{~mL}$ of a beaker containing $50 \mathrm{~mL}$ of $50 \mathrm{ppm}$ phenol. Prior to the photocatalytic reaction, the solution was stirred continuously in the dark condition for $30 \mathrm{~min}$ to reach the equilibrium of adsorption-desorption. The photocatalytic reaction was carried out under solar light simulator irradiation $(150 \mathrm{~W}, \lambda>230 \mathrm{~nm}$, and $\mathrm{I}=$ 110,000 Lux) for $6 \mathrm{~h}$. The final remaining concentration of the solution was determined by using highperformance liquid chromatography (HPLC, Shimadzu, LC-20AT) equipped with a UV detector. The final concentration of phenol was determined using the ratio of degraded phenol to its initial concentration.

\section{- RESULTS AND DISCUSSION}

\section{Effect of Synthesis Temperature}

The XRD patterns of the prepared $\mathrm{CN}-T$ samples are presented in Fig. 1. Based on the spectra, all samples showed crystalline properties with at least one crystalline peak of (210) plane was observed. Two most intense and broad peaks at $2 \theta$ of $c a .27$ and $12^{\circ}$ corresponded to an interlayer distance of graphite-like $\mathrm{CN}$ and distance of the in-plane arrangement of nitrogen-linked heptazine or poly(triazine imide) units, respectively [8-19,24-31]. Both peaks were observed in all samples. The $\mathrm{CN}-500$ showed at least one crystalline peak, which was observed at $2 \theta$ of $c a .31 .9$ (210), indicating the crystallization could be initiated at a temperature of $500{ }^{\circ} \mathrm{C}$.

When the synthesis temperature was increased to $550{ }^{\circ} \mathrm{C}$, more crystalline peaks were visualized, mainly at $2 \theta$ of 20.7 (110), 24.5 (200), 29.3 (102) and $32.4^{\circ}(210)$, owing to the poly(triazine imide) units [15-16,25-26]. Similar crystalline peaks were also observed when the synthesis temperature was increased to $600{ }^{\circ} \mathrm{C}$, but the resulted CN-600 was composed of the hybrid of heptazine-based and poly(triazine imide) units. The amorphous phase (heptazine-based units) was likely to be induced at a higher temperature as can be seen at $2 \theta$ of $27.8^{\circ}$. 


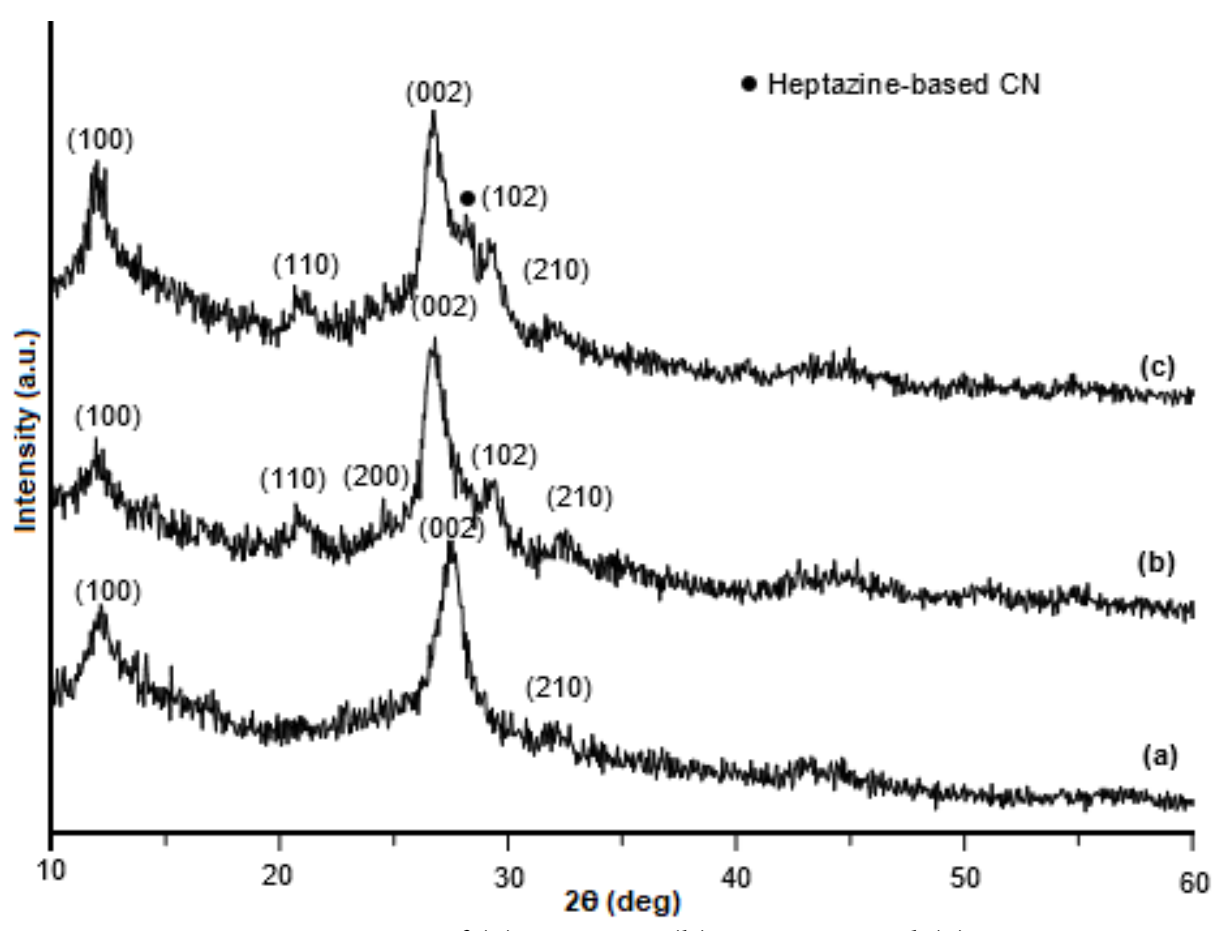

Fig 1. XRD patterns of (a) CN-500, (b) CN-550, and (c) CN-600

It was demonstrated that increasing the synthesis temperature from 500 to $550{ }^{\circ} \mathrm{C}$ resulted in the changes in phase structure from heptazine-based units (amorphous $\mathrm{CN}$ ) to poly(triazine imide) (crystalline $\mathrm{CN}$ ) with high crystalline phase, owing to its high thermal stability compared to amorphous $\mathrm{CN}$ at high temperature in the presence of molten salts. Similar results on the changes of the crystallinity phase were also reported on crystalline $\mathrm{CN}$ prepared by urea-based precursor when temperature variation was carried out [27]. The presence of the amorphous phase at a high temperature $\left(600^{\circ} \mathrm{C}\right)$ might be related to the binary phase properties of $\mathrm{KCl}-\mathrm{LiCl}$. In ionothermal synthesis, the molten salts were required as the ionic solvent for the growth of crystallization. As the temperature increased, the $\mathrm{KCl}-\mathrm{LiCl}$ would consist of a mixture of both solid salts and molten salts. Since more solid salts in the eutectic mixture are formed at high temperature, it is believed that the crystallization could not occur, and thus leading to the formation of heptazinebased units. All these XRD results demonstrated that the crystallinity phase could be tuned via controlling the temperature during the ionothermal synthesis.

The optical properties of the prepared $\mathrm{CN}-T$ photocatalysts were investigated by the DR UV-vis spectrophotometer. Fig. 2 shows the absorption spectra of the $\mathrm{CN}-500$, the $\mathrm{CN}-550$, and the $\mathrm{CN}-600$. Three major peaks were observed in all of the samples. The peak at low region $(c a .260 \mathrm{~nm})$ was attributed to $\mathrm{C}-\mathrm{N}$ indicating the $\pi \rightarrow \pi^{*}$ transition, while the peak at region ca. $320 \mathrm{~nm}$ corresponded to the $\mathrm{C}=\mathrm{O}$ functional group indicating the $\pi \rightarrow \pi^{\star}$ and $\mathrm{n} \rightarrow \pi^{*}$ transitions. The presence of the $\mathrm{C}=\mathrm{O}$ functional group indicated the less condensation of urea precursor during the polymerization process [28]. Meanwhile, the peak at 366 $\mathrm{nm}$ corresponded to the $\mathrm{C}-\mathrm{N}$ functional group $[1,29-$ 31].

The decreased intensity of the $\mathrm{C}=\mathrm{N}$ and $\mathrm{C}-\mathrm{N}$ peaks on the $\mathrm{CN}-500$ was due to the incomplete polymerization of $\mathrm{CN}$. It was worthy to note that the $\mathrm{CN}-550$ showed a decreased intensity of the $\mathrm{C}=\mathrm{O}$ peak, suggesting that the temperature of $550{ }^{\circ} \mathrm{C}$ could eliminate the $\mathrm{C}=\mathrm{O}$ groups and induced the crystallization, forming a highly condensed CN network. When the synthesis temperature was raised to $600{ }^{\circ} \mathrm{C}$, the $\mathrm{CN}-600$ showed the presence of the $\mathrm{C}=\mathrm{O}$ peak, and the absorption edge was slightly increased to a longer wavelength. As shown in Fig. 2, the CN-600 showed absorption up to $450 \mathrm{~nm}$, while sample $\mathrm{CN}-550$ showed absorption up to $430 \mathrm{~nm}$. 


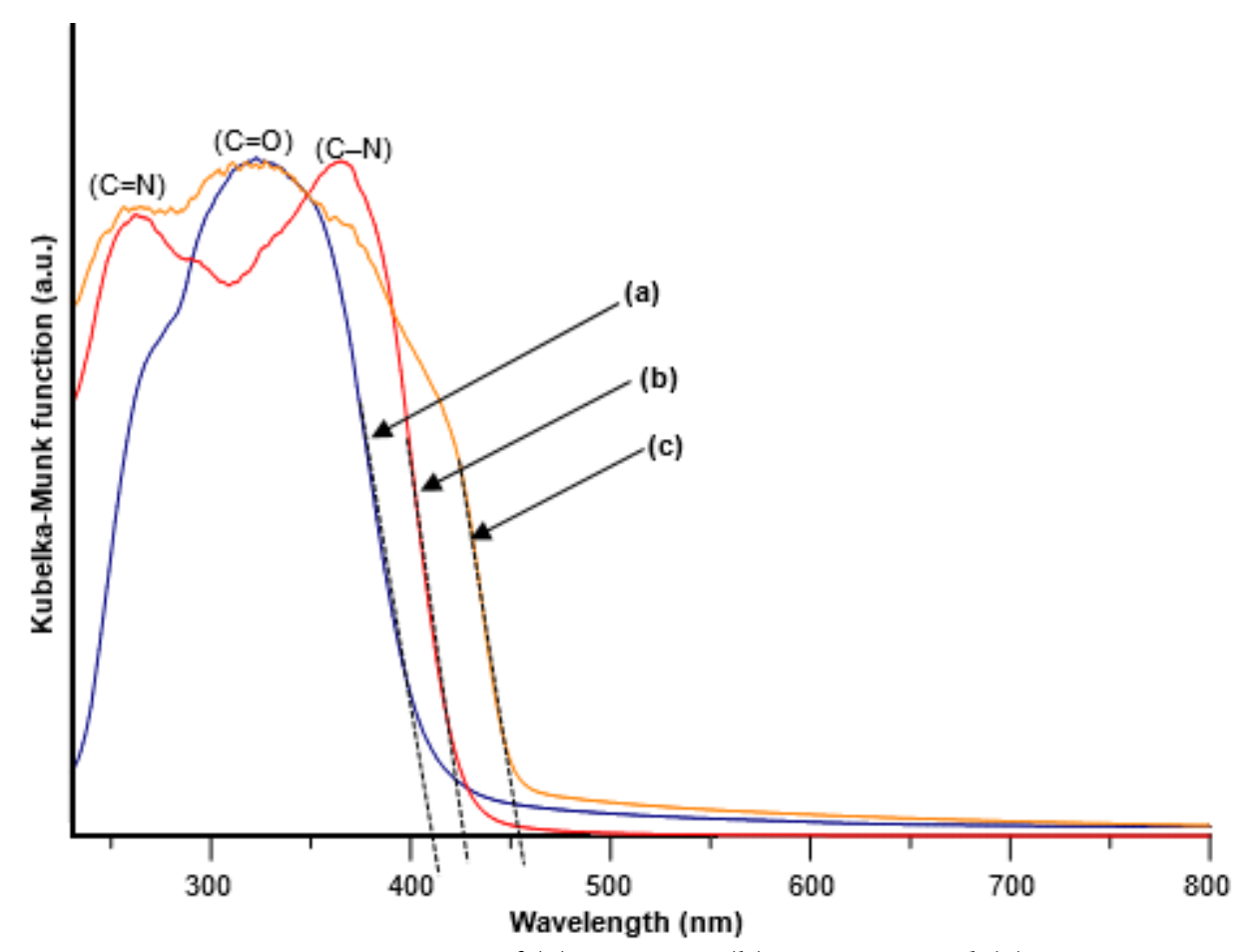

Fig 2. DR UV-vis spectra of (a) CN-500, (b) CN-550, and (c) CN-600

On the other hand, sample $\mathrm{CN}-500$ showed a minimum absorption at region $c a .410 \mathrm{~nm}$. This result demonstrated that increasing the synthesis temperature increased the visible light absorption. The altered optical properties might be related to the color changes of the prepared $\mathrm{CN}$ samples as the $\mathrm{CN}-500$ showed a pale yellow, while the $\mathrm{CN}-550$ and the $\mathrm{CN}-600$ samples showed a yellowish and brownish yellow color, respectively.

It was revealed that the hybrid of heptazine and poly(triazine imide) $\mathrm{CN}$ enhanced the visible light absorption to longer wavelength, indicating a decrease in the band gap energy with increasing the synthesis temperature. Fig. 3 shows the band gap energy of $\mathrm{CN}-\mathrm{T}$ samples estimated from the Tauc plot. The estimated band gap values for $\mathrm{CN}-500, \mathrm{CN}-550$, and $\mathrm{CN}-600$ were $3.05,2.82$, and $2.72 \mathrm{eV}$, respectively. It has been reported that the band gap energy of the material is one of the important properties that can affect the photocatalytic performance [9-10]. Based on Fig. 3, it was shown that the synthesis temperature has a strong impact on the band gap energy values, which could be associated with the photocatalytic activity. As the synthesis temperature increased, the band gap energy of $\mathrm{CN}-\mathrm{T}$ samples was narrowed down, and the visible light absorption was enhanced. These results suggested that the band gap energy of $\mathrm{CN}$ can be tuned by controlling the synthesis temperature.

The characteristics of the chemical bonding and functional groups of the $\mathrm{CN}-\mathrm{T}$ samples were studied by FTIR spectrometer. Fig. 4 shows the FTIR spectra of (CN-500, CN-550, and CN-600. From the spectra, it could be noted that increasing synthesis temperature did not result in significant changes in the functional groups. The peaks observed at the regions of 810 and $1200-700 \mathrm{~cm}^{-1}$ indicated the successful formation of CN heterocycles, thus, suggesting that the $\mathrm{CN}$ material could be synthesized at temperatures ranging from 500 to $600{ }^{\circ} \mathrm{C}$. The peak at $\mathrm{ca} .810 \mathrm{~cm}^{-1}$ corresponded to the bending mode of out-of-plane triazine units, while the multiple bands at $c a .1200-1700 \mathrm{~cm}^{-1}$ corresponded to the stretching mode of heptazine and/or poly(triazine imide) units $[8,11,15,17-21,24-26,28]$.

On the other hand, the formation of both $\mathrm{C} \equiv \mathrm{N}$ and $\mathrm{N}=\mathrm{C}=\mathrm{N}$ at $2170 \mathrm{~cm}^{-1}$ was due to the broke of the $\mathrm{CN}$ continuity network $[8,15,28]$, owing to the intercalation of lithium and chloride ions that resulted in the formation 


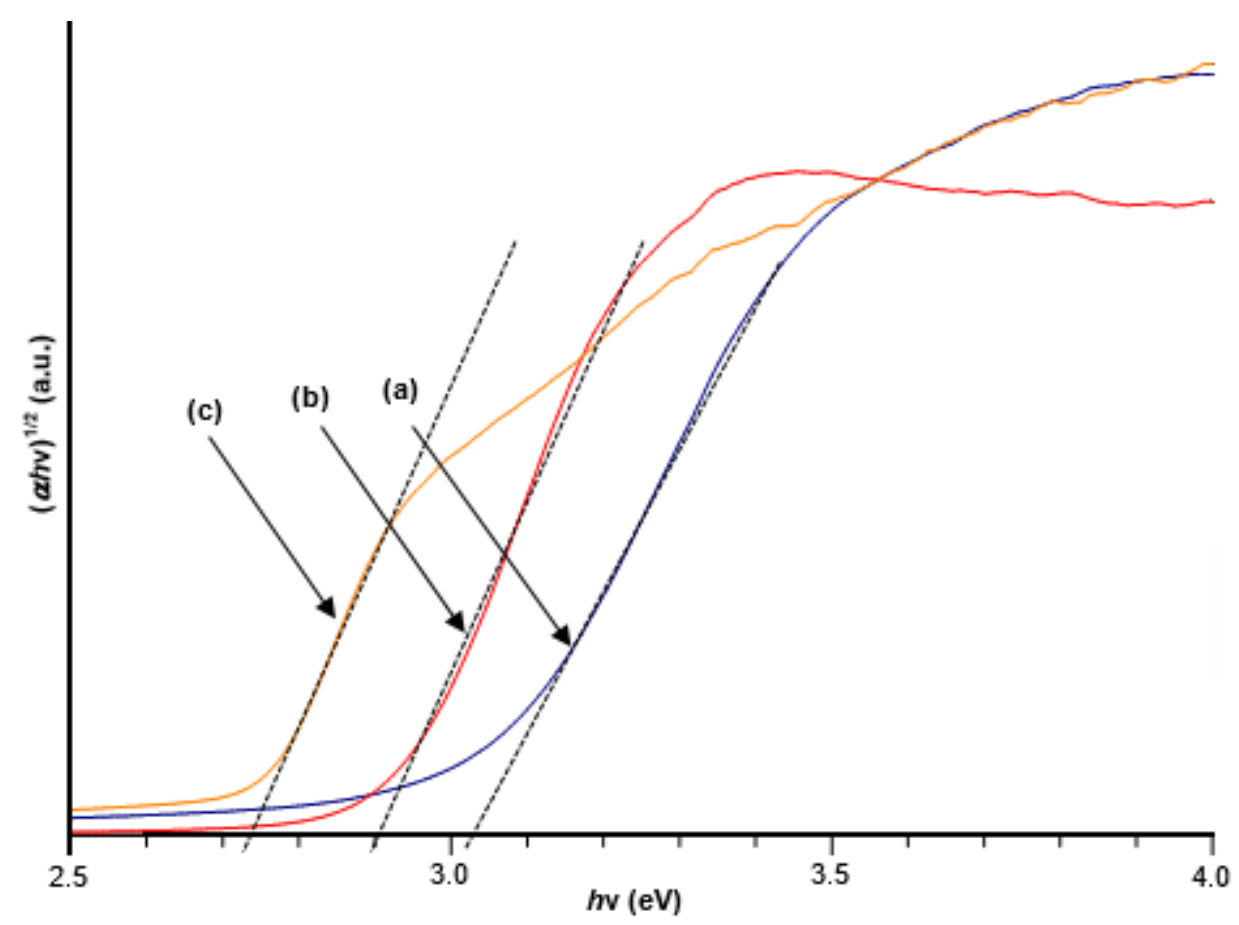

Fig 3. Tauc plots of (a) $\mathrm{CN}-500$, (b) $\mathrm{CN}-550$, and (c) $\mathrm{CN}-600$

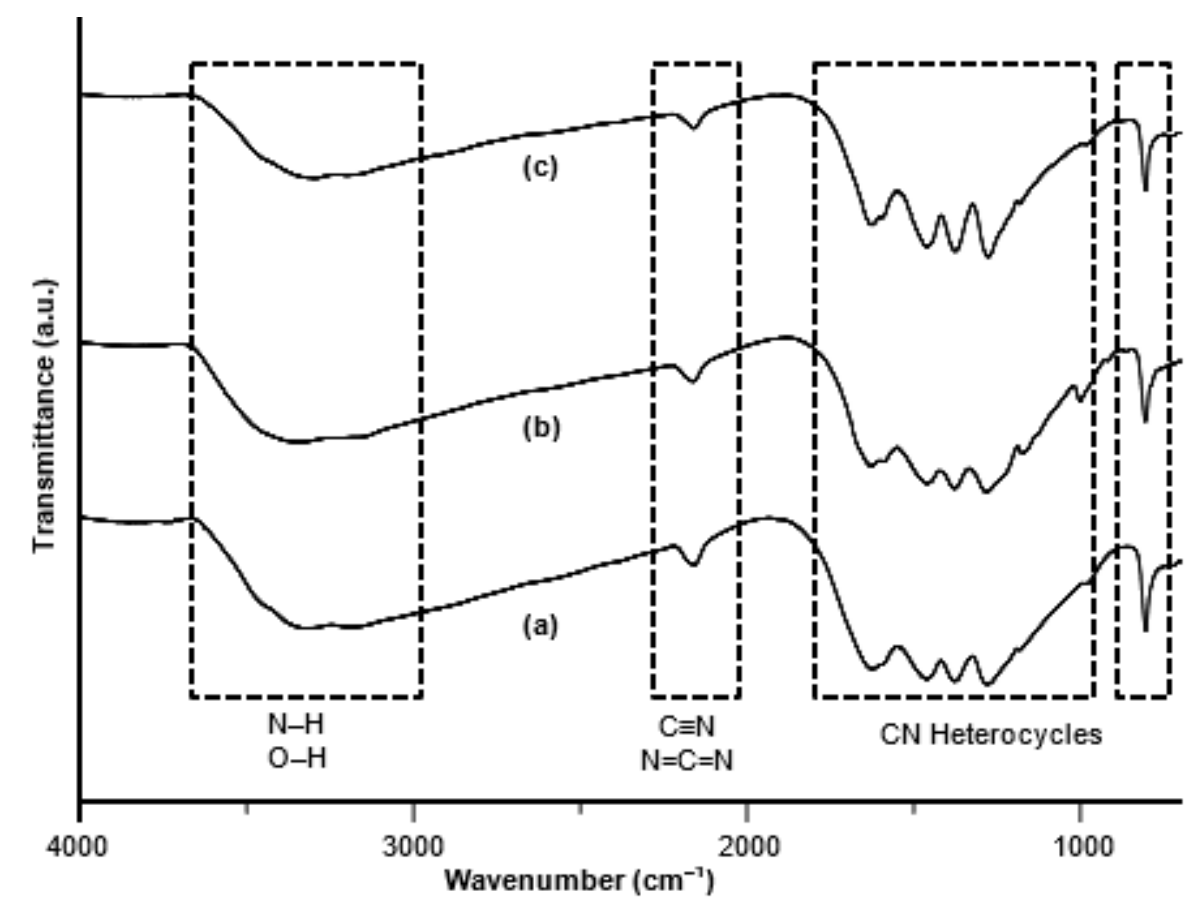

Fig 4. FTIR spectra of (a) $\mathrm{CN}-500$, (b) $\mathrm{CN}-550$, and (c) $\mathrm{CN}-600$

of void channels along with the ABA stacking of poly(triazine imide). Meanwhile, broad bands at around $3000-3700 \mathrm{~cm}^{-1}$ were originated from the overlapping of primary amine and secondary amine, $\mathrm{N}-\mathrm{H}$ and hydroxide, $\mathrm{O}-\mathrm{H}$ groups, respectively. However, it was observed that the intensity of the broad peak that attributed to the stretching modes of the primary and secondary amines and their intermolecular hydrogenbonding interactions $\left(3000-3700 \mathrm{~cm}^{-1}\right)$ reduced as the temperature increased, which especially could be 
observed on the CN-600 (Fig. 4(c)). This result suggested that the final condensation product obtained in high temperature was lacking in terminal unreacted $-\mathrm{NH}_{2}$ groups and was cohesive owing to the effect of covalent interactions.

The textural properties and specific surface area were investigated via nitrogen adsorption-desorption analysis. The isotherms and Barrett-Joyner-Halenda $(\mathrm{BJH})$ pore size distribution (inset) of prepared $\mathrm{CN}-\mathrm{T}$ samples are presented in Fig. 5. All samples showed the type IV isotherm with type $\mathrm{H} 3$ hysteresis loop according to IUPAC classification, suggesting the formation of the porous structure. The Brunauer-Emmett-Teller (BET) specific surface areas of the $\mathrm{CN}-500$, the $\mathrm{CN}-550$, and the $\mathrm{CN}-600$ were 24,73 , and $65 \mathrm{~m}^{2} \mathrm{~g}^{-1}$, respectively. From the BET specific surface area values obtained, it could be suggested that increasing the synthesis temperature from 500 to $550^{\circ} \mathrm{C}$ increased the specific surface area. However, the further increase to $600{ }^{\circ} \mathrm{C}$ caused a slight decrease in the value of the specific surface area.
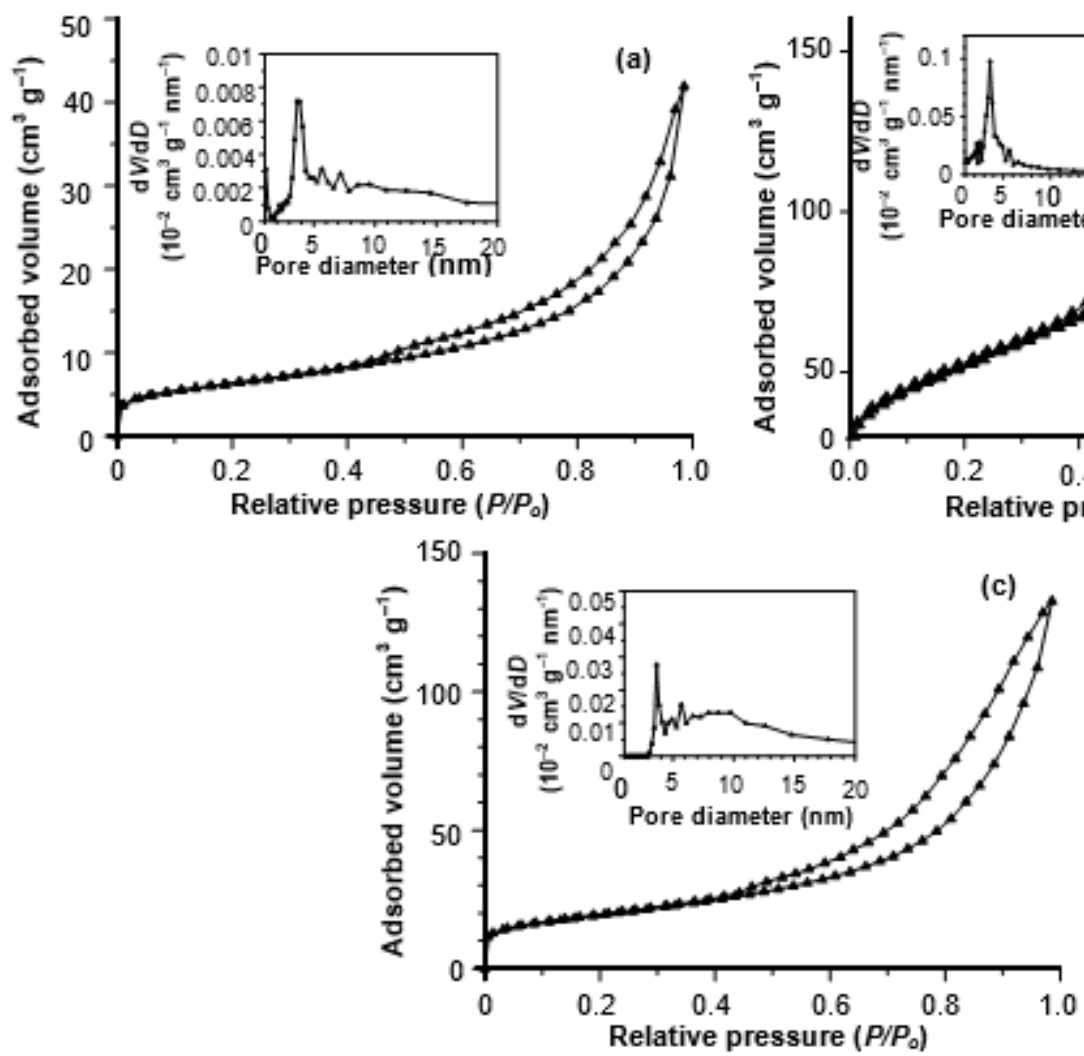

Fig 5. Nitrogen adsorption-desorption isotherms and their respective BJH pore size distribution curves (inset) of (a) $\mathrm{CN}-500$, (b) $\mathrm{CN}-550$, and (c) $\mathrm{CN}-600$

The slight decrease in the surface area of the CN600 might be due to the hybrid composition of heptazinebased $\mathrm{CN}$ and poly(triazine imide). On the other hand, the $\mathrm{CN}-500$ and the $\mathrm{CN}-600$ showed a non-uniform pore size distribution (inset), while the $\mathrm{CN}-550$ showed a uniform pore size distribution as only one sharp and intense peak was observed. Taking account of the most intense and sharp peak, the average pore size diameters for the $\mathrm{CN}-500$, the $\mathrm{CN}-550$, and the $\mathrm{CN}-600$ were determined to be $3.62,3.63$, and $3.62 \mathrm{~nm}$, respectively.

On the contrary, the average pore volume of the $\mathrm{CN}-500$, the $\mathrm{CN}-550$, and the $\mathrm{CN}-600$ were $0.06,0.23$, and $0.19 \mathrm{~cm}^{3} \mathrm{~g}^{-1}$, respectively. It could be seen that the low specific surface area of $\mathrm{CN}-500$ was due to low pore volume. The $\mathrm{CN}-600$ showed a slight decrease in its surface area, which could be associated with its decreased pore volume. Besides, the slight decrease in the specific surface area of the CN-600 might be related to the structural changes of the poly(triazine imide) to the hybrid composition of poly(triazine imide) and heptazine

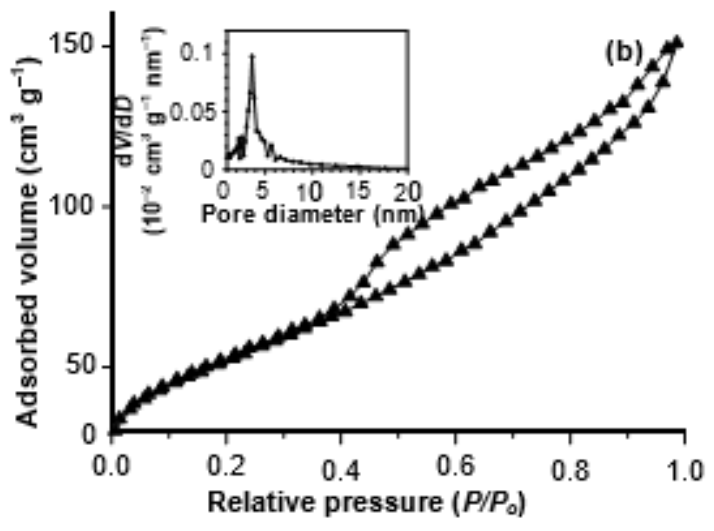

(c) 
units, considering that the amorphous phase tends to reduce the surface area of the material.

Table 1 shows the percentage of phenol degradation on the prepared $\mathrm{CN}-T$ samples after $6 \mathrm{~h}$ of irradiation under solar light. The $\mathrm{CN}-500$, the $\mathrm{CN}-550$, and the $\mathrm{CN}-$ 600 showed the photocatalytic activity of 7,24 , and $20 \%$, respectively. The low photocatalytic activity (7\%) obtained on the $\mathrm{CN}-500$ sample was clearly due to its large band gap energy, very low crystallinity, and low specific surface area. These properties were mainly due to incomplete polymerization and less condensed structure of $\mathrm{CN}$ when synthesized at $500{ }^{\circ} \mathrm{C}$. Meanwhile, the high photocatalytic activity achieved on the CN-550 (24\%) was due to its crystallinity and high surface area and might also be associated with the band gap energy value. It could be proposed here that material with a high crystalline phase could lead to an efficient electron charge transfer and provide more active sites for the reaction of photocatalytic oxidation-reduction to occur. On the other hand, the photocatalytic performance of the $\mathrm{CN}-600$ was slightly dropped (20\%). As compared to the $\mathrm{CN}-500{ }^{\circ} \mathrm{C}$, the $\mathrm{CN}-600$ exhibited high photocatalytic activity due to its crystallinity, surface area, and mainly due to its low band gap energy. However, when compared to $\mathrm{CN}-550{ }^{\circ} \mathrm{C}$, the slightly decreased photocatalytic activity would be due to the decrease in the crystallinity and specific surface area. The decreased band gap energy value of the CN-600 than the $\mathrm{CN}-550$ could not help improving the activity due to such a decrease in crystallinity and surface area. These results demonstrated that the respective chemical and physical properties (crystallinity, band gap energy, and surface area) were significantly dependent on each other. Controlling the synthesis temperature to maintain the chemical and physical properties is needed so that the high photocatalytic performance could be obtained.

\section{Effect of Synthesis Time}

The X-ray diffractometer was used to study the structural properties of the prepared $\mathrm{CN}-t$ samples. The XRD patterns of the prepared $\mathrm{CN}-2 \mathrm{H}, \mathrm{CN}-4 \mathrm{H}$, and $\mathrm{CN}^{-}$ $6 \mathrm{H}$ were presented in Fig. 6 . The two major peaks at a diffraction angle of $2 \theta$ of $c a .26 .9$ (002) and $11.9^{\circ}$ (100) were referred to an interlayer distance of graphite-like $\mathrm{CN}$ and in-plane arrangement of nitrogen-linked heptazine and/or poly(triazine imide) units [8-19,2431]. It was clear that all samples showed crystalline properties as the planes of (110), (200), (102), and (210) were observed [15-16,25-26].

As shown in Fig. 6(a) and (b), increasing synthesis time from 2 to $4 \mathrm{~h}$ increased the crystallinity of the $\mathrm{CN}$. However, a further increase in the synthesis temperature to $6 \mathrm{~h}$ resulted in the reduced peak intensity (Fig. 6(c)). The low crystallinity on sample $\mathrm{CN}-2 \mathrm{H}$ might indicate the polymerization or condensation process of $\mathrm{CN}$ was not sufficient at a short synthesis time. However, when the synthesis time was prolonged to $4 \mathrm{~h}$, the supersaturation of the salt melt was high and thus, induced the crystallization process as well as forming a more condensed product. The decrease in the peak intensity on the $\mathrm{CN}-6 \mathrm{H}$ sample could be due to the competition between the crystal growth and the dissolution. It was also believed that prolong the synthesis temperature might cause the $\mathrm{CN}$ to be partially decomposed. From the XRD patterns, it can be concluded that $4 \mathrm{~h}$ was the optimum reaction time required to synthesize crystalline $\mathrm{CN}$ with the high crystalline phase.

The optical properties of the prepared $\mathrm{CN}-t$ photocatalysts were investigated by the DR UV-vis spectrophotometer. The DR UV-vis spectra of the CN$2 \mathrm{H}$, the $\mathrm{CN}-4 \mathrm{H}$, and the $\mathrm{CN}-6 \mathrm{H}$ are presented in Fig. 7 . For all samples, three absorption peaks corresponded to

Table 1. Properties and percentage of phenol degradation after $6 \mathrm{~h}$ under solar light irradiation for $\mathrm{CN}-\mathrm{T}$ samples

\begin{tabular}{ccccc}
\hline Sample & Crystallinity & $E_{\mathrm{g}}{ }^{1}(\mathrm{eV})$ & $\mathrm{S}^{\mathrm{A}} \mathrm{A}^{2}\left(\mathrm{~m}^{2} \mathrm{~g}^{-1}\right)$ & Degradation $(\%)$ \\
\hline $\mathrm{CN}-500$ & $\times$ & 3.02 & 24 & 7 \\
$\mathrm{CN}-550$ & $\sqrt{ }$ & 2.82 & 73 & 24 \\
$\mathrm{CN}-600$ & $\sqrt{ }$ & 2.72 & 65 & 20 \\
\hline
\end{tabular}

${ }^{1}$ Band gap energy values were determined via the Tauc plot

${ }^{2}$ Specific surface area was determined via the BET technique 


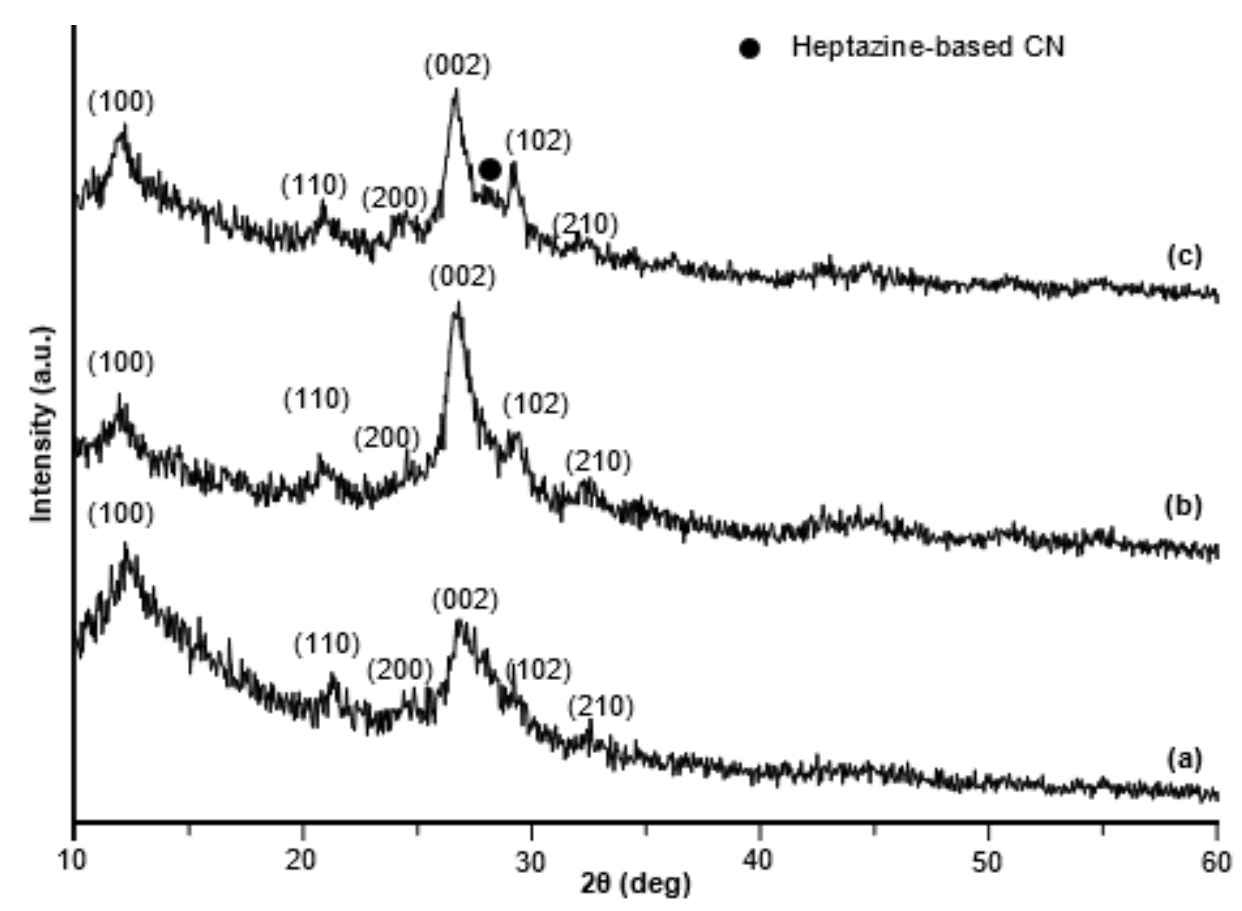

Fig 6. $\mathrm{XRD}$ patterns of (a) $\mathrm{CN}-2 \mathrm{H}$, (b) $\mathrm{CN}-4 \mathrm{H}$, and (c) $\mathrm{CN}-6 \mathrm{H}$

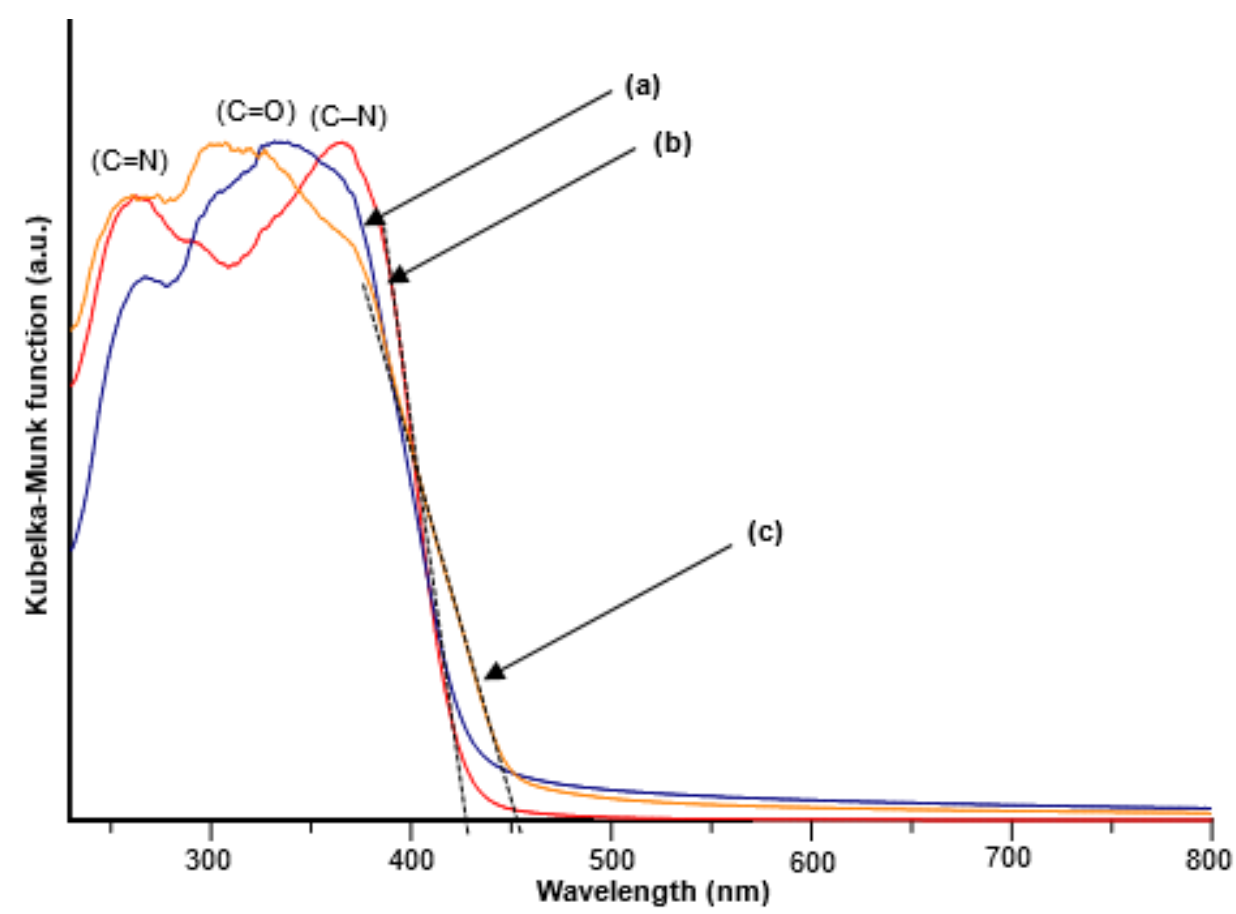

Fig 7. DR UV-vis spectra of (a) $\mathrm{CN}-2 \mathrm{H}$, (b) $\mathrm{CN}-4 \mathrm{H}$, and (c) $\mathrm{CN}-6 \mathrm{H}$

the functional groups of $\mathrm{C}=\mathrm{N}, \mathrm{C}=\mathrm{O}$, and $\mathrm{C}-\mathrm{O}$ were observed at $c a .263,305$, and $360 \mathrm{~nm}$, respectively. Each peak corresponded to $\pi \rightarrow \pi^{*}, \pi \rightarrow \pi^{*}$ and $\mathrm{n} \rightarrow \pi^{\star}$, and $\pi$ $\rightarrow \pi^{\star}$ transitions [8,29-31]. It was observed that the peak of C-N was slightly shifted to a shorter wavelength for the
$\mathrm{CN}-2 \mathrm{H}$. Due to its less condensed and incomplete polymerization, the $\mathrm{CN}-2 \mathrm{H}$ showed a reduced peak intensity, which belonged to the functional group of $\mathrm{C}=\mathrm{N}$. The less condensed product of $\mathrm{CN}$ might be caused by the short reaction time. While the $\mathrm{CN}-2 \mathrm{H}$ and the $\mathrm{CN}-$ 
$4 \mathrm{H}$ have a similar visible light absorption up to $430 \mathrm{~nm}$, the $\mathrm{CN}-6 \mathrm{H}$ showed a slightly shifted absorption toward longer wavelength in the region up to $460 \mathrm{~nm}$. The slight increase in the visible light absorption on sample $\mathrm{CN}-6 \mathrm{H}$ might be due to better crystallinity or $\mathrm{CN}$ framework arrangement, as depicted in Fig. 7(c). The enhanced visible light absorption was also due to the increment in the crystallite size owing to the additional formation of heptazine-based units within the $\mathrm{CN}-6 \mathrm{H}$ sample.

Fig. 8 shows the Tauc plots of the $\mathrm{CN}-2 \mathrm{H}$, the $\mathrm{CN}-$ $4 \mathrm{H}$, and the $\mathrm{CN}-6 \mathrm{H}$ samples. The estimated band gap energy values for each respective sample were 2.90, 2.87, and $2.76 \mathrm{eV}$. These band gap values were in good agreement with crystalline $\mathrm{CN}$ as reported elsewhere using similar precursor except for the synthesis procedure [27]. While the $\mathrm{CN}-2 \mathrm{H}$ and $\mathrm{CN}-4 \mathrm{H}$ gave a close value to each other, the $\mathrm{CN}-6 \mathrm{H}$ showed a lower band gap energy. The decrease in its band gap energy could be associated with the increase in its crystallite size or quantum size effect. The increased crystallite size was occurred due to phase changes from poly(triazine imide) to the hybrid composition of heptazine-based and poly(triazine imide). These results suggested the need for optimum synthesis time in preparing crystalline $\mathrm{CN}$ as shortening the synthesis time would result in less condensed $\mathrm{CN}$ while lengthening the reaction time might cause structural and phase changes of the $\mathrm{CN}$.

The characteristics of chemical bonds and functional groups of the prepared $\mathrm{CN}-t$ photocatalysts were analyzed by FTIR spectrophotometer. Fig. 9 shows the FTIR spectra of the $\mathrm{CN}-2 \mathrm{H}$, the $\mathrm{CN}-4 \mathrm{H}$, and the $\mathrm{CN}-6 \mathrm{H}$ samples. The formation of $\mathrm{CN}$ heterocycles (heptazine and/or poly(triazine imide)) can be observed in both region at ca. 810 and $1200-1700 \mathrm{~cm}^{-1}$ $[8,11,15,17-20,24-26,28]$. The wide and broad peaks at ca. $3000-3700 \mathrm{~cm}^{-1}$ were originated from the overlapping functional groups of $\mathrm{N}-\mathrm{H}$ and $\mathrm{O}-\mathrm{H}$. The presence of the $\mathrm{O}-\mathrm{H}$ functional group was due to absorbed water molecules at the ambient pressure. The band at $c a .810$ $\mathrm{cm}^{-1}$ corresponded to the bending mode of out-of-plane heptazine-based and/or poly(triazine imide) units. The bands at $1200-1700 \mathrm{~cm}^{-1}$ were attributed to the stretching mode of heptazine and/or poly(triazine imide) units.

The small and intense peak appeared at ca. $2170 \mathrm{~cm}^{-1}$ on all samples indicated the formation of $\mathrm{C} \equiv \mathrm{N}$ and $\mathrm{N}=\mathrm{C}=\mathrm{N}$ that were typical for crystalline $\mathrm{CN}$. The formation of both functional groups was due to the broken of the $\mathrm{CN}$ continuity networks $[8,15,28]$, owing to

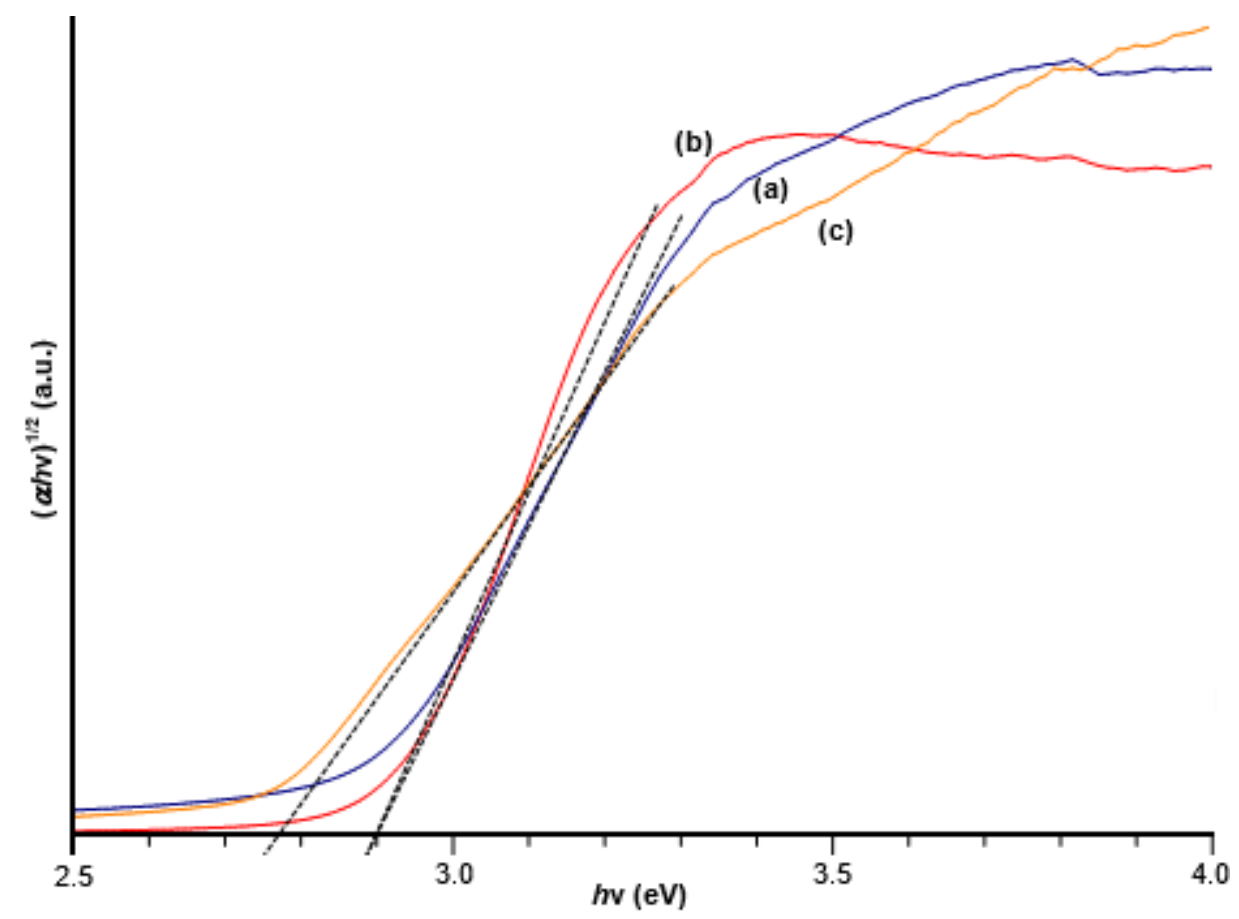

Fig 8. Tauc plots of (a) $\mathrm{CN}-2 \mathrm{H}$, (b) $\mathrm{CN}-4 \mathrm{H}$, and (c) $\mathrm{CN}-6 \mathrm{H}$ 


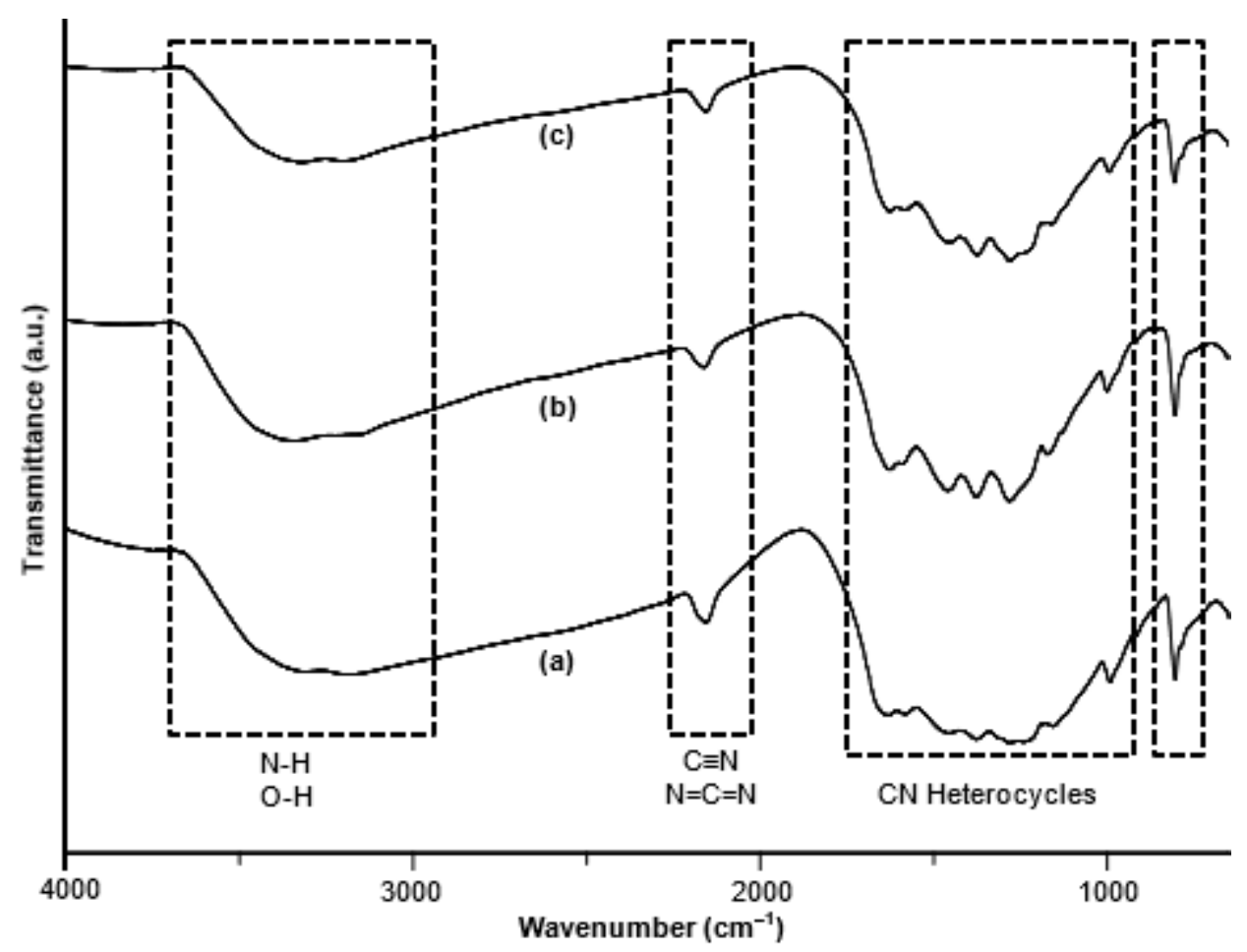

Fig 9. FTIR spectra of (a) $\mathrm{CN}-4 \mathrm{H}$, (b) $\mathrm{CN}-6 \mathrm{H}$, and (c) $\mathrm{CN}-6 \mathrm{H}$

the intercalation of lithium and chloride ions. From the spectra, it can be observed that the less intense peaks of $\mathrm{CN}$ heterocycles in the region of $1200-1700 \mathrm{~cm}^{-1}$ for the $\mathrm{CN}-2 \mathrm{H}$ sample (Fig. 9(a)) suggested the incomplete formation or less condensed of $\mathrm{CN}$ networks due to a short synthesis time. Moreover, increasing synthesis time from 4 to $6 \mathrm{~h}$ showed that the $\mathrm{CN}$ network structure was decomposed as the peak intensity attributed to $\mathrm{CN}$ heterocycles was decreased (Fig. 9(c)). These results demonstrated that short reaction time caused the incomplete formation of $\mathrm{CN}$, while long synthesis time may cause the decomposition of the $\mathrm{CN}$.

The textural properties of the prepared $\mathrm{CN}-t$ samples were studied via nitrogen adsorption-desorption analysis. The isotherms of each prepared photocatalyst are shown in Fig. 10, while the BJH pore size distribution was shown in the inset of each figure. All samples showed the type IV isotherm with the H3 hysteresis loop, suggesting the presence of the porous structure. From the values of BET specific surface area, increasing synthesis time from 2 to $4 \mathrm{~h}$ resulted in the noteworthy increase of the specific surface area from 30 to $73 \mathrm{~m}^{2} \mathrm{~g}^{-1}$, while further increment of synthesis time to $6 \mathrm{~h}$ caused the specific surface area was slightly dropped to $55 \mathrm{~m}^{2} \mathrm{~g}^{-1}$.

The low surface area on the $\mathrm{CN}-2 \mathrm{H}$ sample was due to less condensed or incomplete polymerization of $\mathrm{CN}$. This suggested that $4 \mathrm{~h}$ of synthesis time was the optimum time to form a highly condensed $\mathrm{CN}$ product. In addition, the slightly reduced surface area when prolonging the synthesis time was due to the formation of the hybrid heptazine-based and poly(triazine imide) unit. A similar result was also reported when structural and composition changes were observed [27]. From the insets of the figure, the $\mathrm{BJH}$ pore size distribution analysis showed that all samples were uniformly porous with the average sizes of $3.83,3.62$, and $3.62 \mathrm{~nm}$ for the $\mathrm{CN}-2 \mathrm{H}$, the $\mathrm{CN}-4 \mathrm{H}$, and the $\mathrm{CN}-6 \mathrm{H}$, respectively. Meanwhile, the average pore volumes calculated via the $\mathrm{BJH}$ equation were $0.06,0.23$, and $0.1 \mathrm{~cm}^{3} \mathrm{~g}^{-1}$, respectively. The difference in the pore size between the $\mathrm{CN}-2 \mathrm{H}$ and both the $\mathrm{CN}-4 \mathrm{H}$ and the $\mathrm{CN}-6 \mathrm{H}$ might be due to the limited growth of crystalline $\mathrm{CN}$ that was associated with less condensed and incomplete polymerization process. 

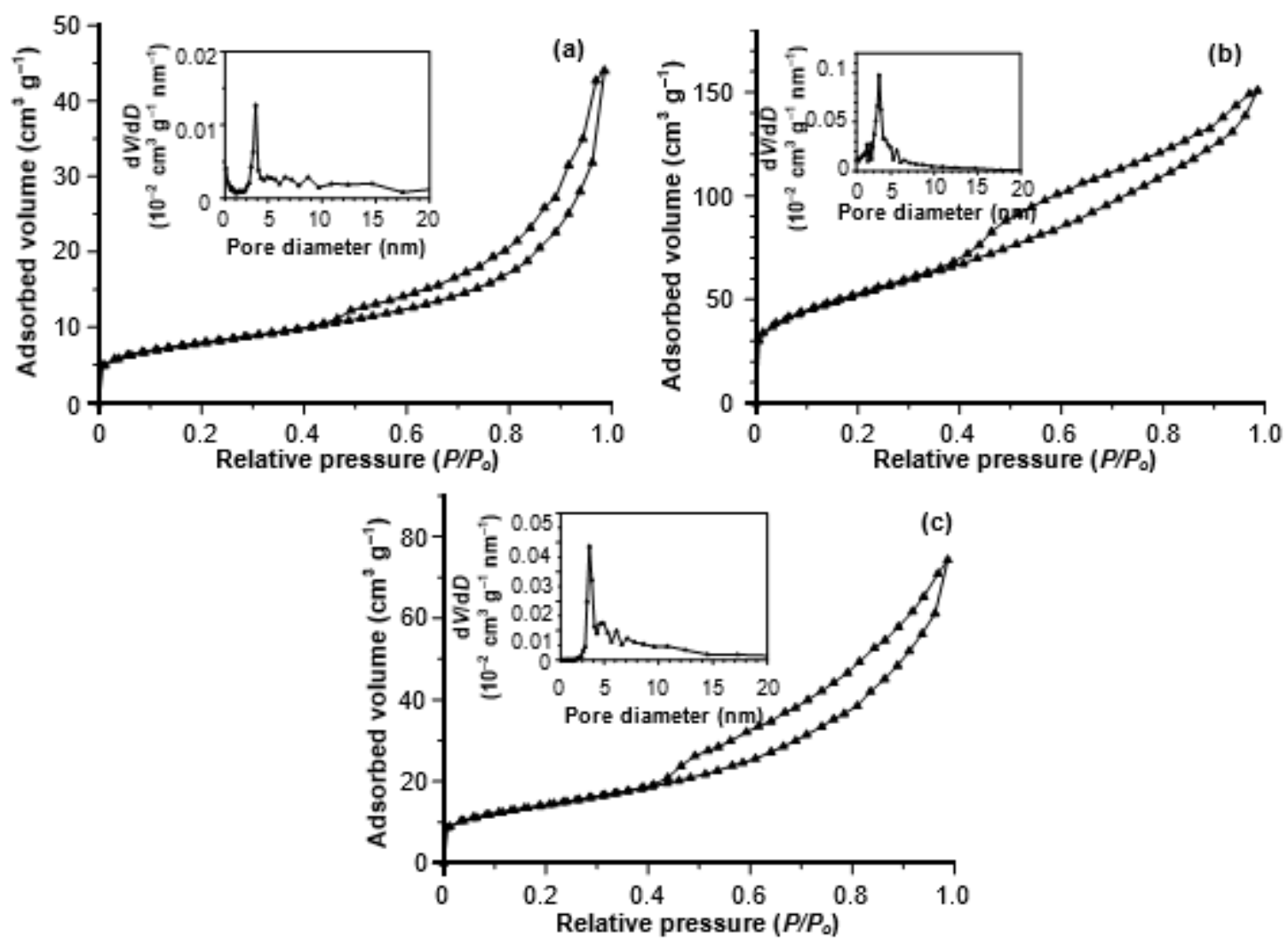

Fig 10. Nitrogen adsorption-desorption isotherms and their respective $\mathrm{BJH}$ pore size distribution curves (inset) of (a) $\mathrm{CN}-2 \mathrm{H}$, (b) $\mathrm{CN}-4 \mathrm{H}$, and (c) $\mathrm{CN}-6 \mathrm{H}$

Table 2. Properties and percentage of phenol degradation after 6 hours under solar simulator irradiation for $\mathrm{CN}-t$ samples

\begin{tabular}{ccccc}
\hline Sample & Crystallinity $^{1}(\%)$ & $E_{\mathrm{g}}{ }^{2}(\mathrm{eV})$ & $\mathrm{S}^{\mathrm{A}} \mathrm{A}^{3}\left(\mathrm{~m}^{2} \mathrm{~g}^{-1}\right)$ & Degradation (\%) \\
\hline $\mathrm{CN}-2 \mathrm{H}$ & 86 & 2.90 & 30 & 17 \\
$\mathrm{CN}-4 \mathrm{H}$ & 100 & 2.82 & 73 & 24 \\
$\mathrm{CN}-6 \mathrm{H}$ & 90 & 2.76 & 55 & 20 \\
\hline
\end{tabular}

${ }^{1}$ Percentage of crystallinity was calculated via the following formula: Crystallinity (\%) = (total area of crystalline peaks)/(total area of all peaks). The percentage of crystallinity of sample $\mathrm{CN}-4 \mathrm{H}$ was taken into account as $100 \%$

${ }^{2}$ Band gap energy values were determined via the Tauc plot

${ }^{3}$ Specific surface areas were determined via the BET technique

Table 2 lists the chemical and physical properties and photocatalytic activity of the $\mathrm{CN}-t$ samples after $6 \mathrm{~h}$ irradiation under solar light. As shown in the table, the high photocatalytic activity was achieved on the $\mathrm{CN}-4 \mathrm{H}$ sample with $24 \%$ of phenol degradation within $6 \mathrm{~h}$ of irradiation, while the $\mathrm{CN}-2 \mathrm{H}$ and the $\mathrm{CN}-6 \mathrm{H}$ samples showed phenol degradation of 17 and $20 \%$, respectively. Increasing the synthesis time from 2 to $4 \mathrm{~h}$ resulted in the lower band gap energy. However, the photocatalytic activity of the $\mathrm{CH}-6 \mathrm{H}$ did not further increase since the surface area decreased from 73 to $55 \%$. The high photocatalytic activity obtained by $\mathrm{CN}-4 \mathrm{H}$ sample compared to $\mathrm{CN}-$ $2 \mathrm{H}$ and $\mathrm{CN}-6 \mathrm{H}$ was coming from the crystallinity of the materials, suitable band gap energy, and high surface area. These results suggested that the synthesis time affected the properties of crystallinity, band gap energy, and surface area. Synthesis time of $4 \mathrm{~h}$ was important to obtain a CN sample with improved crystallinity, suitable low band gap energy while maintaining the high surface area to achieve a photocatalyst with high activity. 


\section{Optimized Synthesis Temperature and Time}

As shown in Table 1 and 2, the optimized synthesis temperature and time that gave optimized photocatalytic activity were $550{ }^{\circ} \mathrm{C}$ and $4 \mathrm{~h}$, respectively. Both optimization studies showed that the best photocatalytic activity was obtained when the $\mathrm{CN}$ has good crystallinity, enough low band gap energy, and high specific surface area. In order to study the morphology of the crystalline $\mathrm{CN}$ obtained under these optimized synthesis conditions, the TEM image was recorded and shown in Fig. 11. It was obvious that the prepared crystalline $\mathrm{CN}$ gave a nearhexagonal prismatic crystallite with a size of about $50 \mathrm{~nm}$. This morphology was certainly different from the reported spherical shape or worm structures of the amorphous bulk or mesoporous $\mathrm{CN}$ [8].

As we compare the photocatalytic activity of the crystalline $\mathrm{CN}$ to the $\mathrm{TiO}_{2}$ P25 as the benchmark photocatalyst so far [2], the performance of the crystalline $\mathrm{CN}$ to degrade phenol could be considered low. However, the activity of the $\mathrm{TiO}_{2} \mathrm{P} 25$ is mainly generated under UV light irradiation, which would be one of the limitations to fully utilize the solar light spectrum. On the other hand, while the crystalline $\mathrm{CN}$ could be activated by visible light, its efficiency still needs to be improved. In this work, a clear enhancement in the photocatalytic activity could be achieved, where up to 3.4 times higher degradation percentage was obtained on the crystalline $\mathrm{CN}$ synthesized under optimized temperature and time as

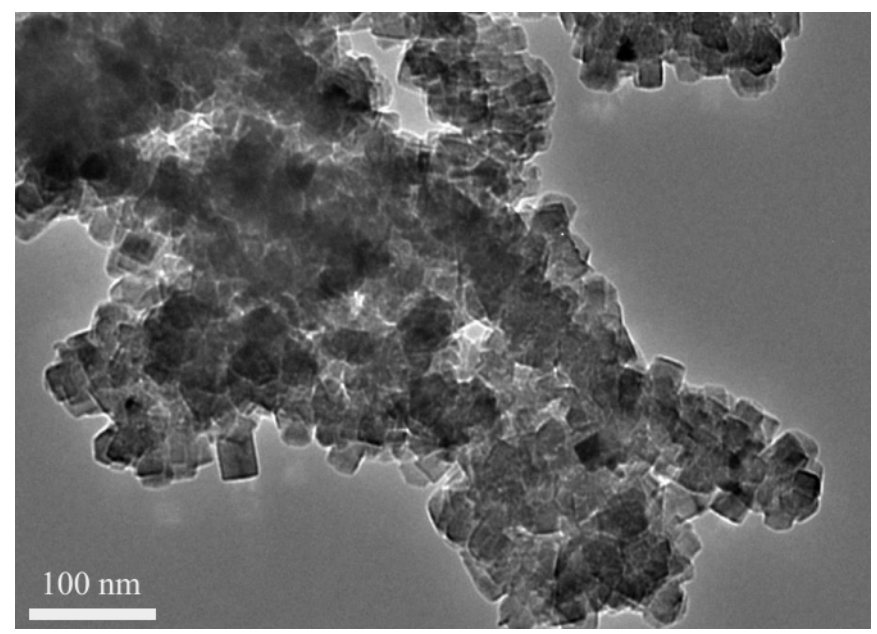

Fig 11. TEM image of crystalline $\mathrm{CN}$ prepared at $550{ }^{\circ} \mathrm{C}$ and $4 \mathrm{~h}$ compared to the ones synthesized under non-optimized conditions. Such improvement was comparable to the reported approach to increase the photocatalytic activity of the amorphous $\mathrm{CN}$, for example, by modifying the interfacial charge transfer of the amorphous $\mathrm{CN}$ by reduced graphene oxide, which gave about 2.8 times better performance for photocatalytic degradation of phenol [31]. This study clearly showed that optimizing the synthesis method is an important strategy to optimize the performance of the photocatalyst.

\section{- CONCLUSION}

Crystalline $\mathrm{CN}$ materials were successfully synthesized at various temperatures $\left(500-600{ }^{\circ} \mathrm{C}\right)$ and various synthesis time (4-6 h). Judging from the photocatalytic performance, the best parameters for synthesis temperature and time were $550{ }^{\circ} \mathrm{C}$ and $4 \mathrm{~h}$, respectively. The characterizations by XRD, DR UV-vis, and surface area analyzer revealed that these parameters led to the high crystallinity, enough low band gap energy $(2.82 \mathrm{eV})$, and high specific surface area $\left(73 \mathrm{~m}^{2} \mathrm{~g}^{-1}\right)$, which resulted in up to 3.4 times higher percentage of phenol degradation than the ones synthesized under the non-optimized synthesis conditions.

\section{- ACKNOWLEDGMENTS}

Support from the Directorate General of Strengthening Research and Development, Ministry of Research, Technology, and Higher Education of the Republic of Indonesia via the Fundamental Research scheme (PD 2019, No. 058/SP2H/LT/MONO/L7/2019 and No. 001/MACHUNG/LPPM/SP2H-LIT-MONO/ III/2019) is greatly acknowledged.

\section{- REFERENCES}

[1] Villegas, L.G.C., Mashhadi, N., Chen, M., Mukherjee, D., Taylor, K.E., and Biswas, N., 2016, A short review of techniques for phenol removal from wastewater, Curr. Pollut. Rep., 2 (3), 157-167.

[2] Barka, N., Bakas, I., Qourzal, S., Assabbane, A., and Ait-Ichou, Y., 2013, Degradation of phenol in water by titanium dioxide photocatalysis, Orient. J. Chem., 29 (3), 1055-1060. 
[3] Fajriati, I., Mudasir, and Wahyuni, E.T., 2014, Photocatalytic decolorization study of methyl orange by $\mathrm{TiO}_{2}$-chitosan nanocomposites, Indones. J. Chem., 14 (3), 209-218.

[4] Yuliati, L., Roslan, N.A., Siah, W.R., and Lintang, H.O., 2017, Cobalt oxide-modified titanium dioxide nanoparticle photocatalyst for degradation of 2,4dichlorophenoxyacetic acid, Indones. J. Chem., 17 (2), 284-290.

[5] Kunarti, E.S., Kartini, I., Syoufian, A., and Widyandari, K.M., 2018, Synthesis and photoactivity of $\mathrm{Fe}_{3} \mathrm{O}_{4} / \mathrm{TiO}_{2}$-Co as a magnetically separable visible light responsive photocatalyst, Indones. J. Chem., 18 (3), 403-410.

[6] Vianney, Y.M., Rosalyn, I., and Angela, S., 2018, Solar based photocatalytic decolorization of four commercial reactive dyes utilizing bound $\mathrm{TiO}_{2}-\mathrm{Fe}_{3} \mathrm{O}_{4}$ nanocomposite, Indones. J. Chem., 18 (4), 621-631.

[7] Khoriah, K., Wellia, D.V., Gunlazuardi, J., and Safni, S., 2020, Photocatalytic degradation of commercial diazinon pesticide using $\mathrm{C}, \mathrm{N}$-codoped $\mathrm{TiO}_{2}$ as photocatalyst, Indones. J. Chem., 20 (3), 587-596.

[8] Lee, S.C., Lintang, H.O., and Yuliati, L., 2012, A urea precursor to synthesize carbon nitride with mesoporosity for enhanced activity in the photocatalytic removal of phenol, Chem. Asian J., 7 (9), 2139-2144.

[9] Wang, Y., Wang, X., and Antonietti, M., 2012, Polymeric graphitic carbon nitride as a heterogeneous organocatalyst: From photochemistry to multipurpose catalysis to sustainable chemistry, Angew. Chem. Int. Ed., 51 (1), 68-89.

[10] Zhang, Y., Liu, J., Wu, G., and Chen, W., 2012, Porous graphitic carbon nitride synthesized via direct polymerization of urea for efficient sunlightdriven photocatalytic hydrogen production, Nanoscale, 4 (17), 5300-5303.

[11] Zhao, Y., Zhao, F., Wang, X., Xu, C., Zhang, Z., Shi, G., and Qu, L., 2014, Graphitic carbon nitride nanoribbons: Graphene-assisted formation and synergic function for highly efficient hydrogen evolution, Angew. Chem. Int. Ed., 53 (50), 1393413939.
[12] Zhu, J., Xiao, P., Li, H., and Carabineiro, S.A.C., 2014, Graphitic carbon nitride: Synthesis, properties, and applications in catalysis, ACS Appl. Mater. Interfaces, 6 (19), 16449-16465.

[13] Cui, Y., Huang, J., Fu, X., and Wang, X., 2012, Metal-free photocatalytic degradation of 4chlorophenol in water by mesoporous carbon nitride semiconductors, Catal. Sci. Technol., 2 (7), 1396-1402.

[14] Zheng, Y., Liu, J., Liang, J., Jaroniec, M., and Qiao, S.Z., 2012, Graphitic carbon nitride materials: Controllable synthesis and applications in fuel cells and photocatalysis, Energy Environ. Sci., 5 (5), 6717-6731.

[15] Hatta, M.H.M., Lintang, H.O., Lee, S.L., and Yuliati, L., 2019, Synthesis of highly active crystalline carbon nitride prepared in various salt melts for photocatalytic degradation of phenol, Turk. J. Chem., 43, 63-72.

[16] Bhunia, M.K., Yamauchi, K., and Takanabe, K., 2014, Harvesting solar light with crystalline carbon nitrides for efficient photocatalytic hydrogen evolution, Angew. Chem. Int. Ed., 53 (41), 11001-11005.

[17] Huang, S., Xu, Y., Ge, F., Tian, D., Zhu, X., Xie, M., $\mathrm{Xu}, \mathrm{H}$., and Li, H., 2019, Tailoring of crystalline structure of carbon nitride for superior photocatalytic hydrogen evolution, J. Colloid Interface Sci., 556, 324-334.

[18] Li, Y., Zhang, D., Feng, X., and Xiang, Q., 2020, Enhanced photocatalytic hydrogen production activity of highly crystalline carbon nitride synthesized by hydrochloric acid treatment, Chin. J. Catal., 41 (1), 21-30.

[19] Wang, L., Hong, Y., Liu, E., Wang, Z., Chen. J., Yang, S., Wang, J., Lin, X., and Shi, J., 2020, Rapid polymerization synthesizing high-crystalline $\mathrm{g}-\mathrm{C}_{3} \mathrm{~N}_{4}$ towards boosting solar photocatalytic $\mathrm{H}_{2}$ generation, Int. J. Hydrogen Energy, 45 (11), 6425-6436.

[20] Shalom, M., Inal, S., Fettkenhauer, C., Neher, D., and Antonietti, M., 2013, Improving carbon nitride photocatalysis by supramolecular preorganization of monomers, J. Am. Chem. Soc., 135 (19), 71187121 . 
[21] Prins, L.J., Reinhoudt, D.N., and Timmerman, P., 2001, Noncovalent synthesis using hydrogen bonding, Angew. Chem. Int. Ed., 40 (13), 2382-2426.

[22] Seto, C.T., Mathias, J.P., and Whitesides, G.M., 1993, Molecular self-assembly through hydrogen bonding: Aggregation of five molecules to form a discrete supramolecular structure, J. Am. Chem. Soc., 115 (4), 1321-1329.

[23] Çelik, V., and Mete, E., 2012, Range-separated hybrid exchange-correlation functional analyses of anatase $\mathrm{TiO}_{2}$ doped with W, N, S, W/N, or W/S, Phys. Rev. B: Condens. Matter, 86, 205112.

[24] Lin, L., Yu, Z., and Wang, X., 2018, Crystalline carbon nitride semiconductors for photocatalytic water splitting, Angew. Chem. Int. Ed., 58 (19), 6164-6175.

[25] Bojdys, M.J., Müller, J.O., Antonietti, M.A., and Thomas, A., 2008, Ionothermal synthesis of crystalline, condensed, graphitic carbon nitride, Chem. Eur. J., 14 (27), 8177-8182.

[26] Fettkenhauer, C., Weber, J., Antonietti, M., and Dontsova, D., 2014, Novel carbon nitride composites with improved visible light absorption synthesized in $\mathrm{ZnCl}_{2}$-based salt melts, RSC Adv., 4 (77), 4080340811.

[27] Jin, A., Jia, Y., Chen, C., Liu, X., Jiang, J., Chen, X., and Zhang, F., 2017, Efficient photocatalytic hydrogen evolution on band structure tuned polytriazine/heptazine based carbon nitride heterojunctions with ordered needle-like morphology achieved by an in situ molten salt method, J. Phys. Chem. C, 121 (39), 21497-21509.

[28] Liu, J., Zhang, T., Wang, Z., Dawson, G., and Chen, W., 2011, Simple pyrolysis of urea into graphitic carbon nitride with recyclable adsorption and photocatalytic activity, J. Mater. Chem., 21 (38), 14398-14401.

[29] Sam, M.S., Lintang, H.O., Sanagi, M.M., Lee, S.L., and Yuliati, L., 2014, Mesoporous carbon nitride for adsorption and fluorescence sensor of $\mathrm{N}$ nitrosopyrrolidine, Spectrochim. Acta, Part A, 124, 357-364.

[30] Alim, N.S., Lintang, H.O., and Yuliati, L., 2015, Fabricated metal-free carbon nitride characterizations for fluorescence chemical sensor of nitrate ions, Jurnal Teknologi, 76 (13), 1-6.

[31] Tiong, P., Lintang, H.O., Endud, S., and Yuliati, L., 2015, Improved interfacial charge transfer and visible light activity of reduced graphene oxidegraphitic carbon nitride photocatalysts, $R S C A d v$., 5 (114), 94029-94039. 